\title{
PROCEDURE FOR THE ASSESSMENT OF COGNITIVE COMPLEXITY: DEVELOPMENT AND IMPLEMENTATION IN THE TOPIC "HYDROLYSIS OF SALTS"
}

\author{
Saša A. Horvat", Jovana Mihajlović, Tamara N. Rončević, Dušica D. Rodić \\ Faculty of Sciences, University of Novi Sad, Trg Dositeja Obradovića 3, 21000 Novi Sad, Serbia \\ sasa.horvat@dh.uns.ac.rs
}

\begin{abstract}
The aim of this research was the creation and validation of a procedure for determining the cognitive complexity of problem tasks in the field of salt hydrolysis. The procedure created included an assessment of the difficulty of concepts and an assessment of their interactivity. One of the research tasks was to determine whether there were misconceptions by students that might have influenced their achievement. There were 50 Bachelor of Science in Chemistry students who participated in the study. A knowledge test was used as a research instrument to assess the performance and a seven-point Likert scale to evaluate the invested mental effort. The validity of this instrument for the assessment of cognitive complexity was confirmed by a series of regression analyses, where acceptable and statistically significant correlation coefficients were obtained among the examined variables: student performance and invested mental effort as dependent variables and cognitive complexity as independent variable.
\end{abstract}

Keywords: mental effort; performance; cognitive complexity; salt hydrolysis

\section{ПОСТАПКА ЗА ПРОЦЕНА НА КОГНИТИВНА КОМПЛЕКСНОСТ: РАЗРАБОТКА И ИМПЛЕМЕНТАЦИЈА НА ТЕМАТА „ХИДРОЛИЗА НА СОЛИ“}

\begin{abstract}
Целта на ова истражување е создавање и валидација на постапка за определување на когнитивната комплексност на проблематични поими од областа на хидролиза на соли. Создадената постапка вклучува процена на концептите и процена на нивната интерактивност. Една од истражувачките задачи беше да се определи дали постојат мисконцепции од страна на студентите што можат да влијаат врз нивниот успех. Во оваа студија учествуваа 50 студенти на додипломски студии по хемија. Како истражувачки инструмент беше употребен тест по знаење за да се проценат постигнувањата, а беше применета Ликертова скала за да се процени вложениот ментален напор. Валидноста на овој инструмент за процена на когнитивната комплексност беше потврдена со серија регресиони анализи при што беа добиени прифатливи и статистички значајни коефициенти на корелација меѓу испитуваните променливи: постигнување на студентите и вложен ментален напор како зависно променливи и когнитивната комплексот како независно променлива.
\end{abstract}

Клучни зборови: ментален напор; постигнување; когнитивна комплексност; хидролиза на соли

\section{INTRODUCTION}

Many students find chemistry difficult to learn because they have limited informal, everyday experience with chemistry. Due to the nature of chemistry as a subject, and the complexity of the concepts themselves, it might be difficult for students to connect everyday concepts and experienc- es with chemistry [1]. This distinguishes chemistry from other natural sciences such as physics and biology. In physics it is easy to connect the concept of force with the concept of velocity, or free-fall with gravity, and in biology students understand that plant growth is induced by taking nutrients from the ground and energy from the sun. Understanding key chemical concepts is important when 
learning chemistry in a variety of contexts. One such concept is the concept of acids and bases [1], which is used by students in their everyday life, and therefore it is important that they master this concept successfully and understand concepts such as solution, redox reactions and chemical equilibrium [2]. The concept of acids and bases is one of the oldest in general chemistry [3] and teaching begins in elementary school and later is expanded at higher education levels. No matter how significant this concept is, many studies show that it creates problems for students [2].

The concept closely related to that of acids and bases is the hydrolysis of salts [4]. Poor understanding of this concept and a lack of prior knowledge of the concept of acids and bases has led researchers to observe some misconceptions. This concept is very abstract at the submicroscopic level of chemical content representation [5]. In addition, it is commonly represented in daily life in processes such as water purification, soap dissolution, fertilizer production, etc. Hydrolysis is the most important part of acid-base reactions and is very complex. Knowledge of the properties of reactants and products, the process of dissociation, and chemical equilibrium are required for an understanding of this concept. The concept of hydrolysis of salts is only partially addressed in secondary schools, so that in the continuation of their education students have significant difficulties [4]. It is thought that language and culture can influence different perceptions of this concept among students [6]. Research conducted in high school classes in Azerbaijan found that more than half of the students were not familiar with the concept of salt hydrolysis [7]. Under hydrolysis, they consider the separation of compounds to ions by water and think that water is the cause of that separation, thus explaining hydrolysis as the ionic dissolution of substances in water. Students think that salts cannot be acidic or basic because, in that case such compounds should be called acids or bases, not salts. Most students misunderstand the concept of neutralization referred to in this research [7]. Students claim that neutralization always gives a neutral product at the end of all neutralization reactions. They also claim that if one of the reactants is weak then the neutralization is not complete, even if the reactants are in stoichiometric amounts. Students are unable to connect to the concepts of hydrolysis and the buffer solution, and they find that the concepts are independent [8]. In textbooks used for teaching high school chemistry in the Republic of Serbia, there is no topic entitled "Hydrolysis of salts". This concept is mostly addressed within the topic "Acid-base properties of salt solutions" in the first grade of secondary education. It is also studied in the second grade of secondary education within the topic "Chemical reactions and periodicity". Because of that, students have difficulty in correlating vertically their knowledge of salt hydrolysis [9]. Lack of information in the textbooks allows a superficial appreciation of facts that are not embedded in the cognitive structure of the students, leading to rapid forgetting [5]. Students, in addition to calculating the $\mathrm{pH}$ value of a salt solution, have a problem with understanding hydrolysis reactions, which are especially difficult for highschool students [4]. Research shows that they avoid writing ionic equations and prefer to write them in the molecular form [10]. It has been shown that students have difficulties in writing the hydrolysis reactions of ions because they usually wrote down acids and bases using molecular formulas [11]. It was found that students had little knowledge of the hydrolysis process, besides the definition: "It is a reaction of a substance with water". Along with a lack of understanding of the hydrolysis process and ionic reactions, it is difficult for students to understand and write the equations of the chemical reactions of ions that show acidic or basic character in aqueous solution [11].

Many chemical concepts, such as salt hydrolysis, are highly abstract and have a mathematical basis [12]. The cognitive demand for working memory resources when processing highly abstract concepts is one of the main reasons why chemistry is difficult. Cognitive load theory is considered to be one of the most significant theories in the field of learning and teaching that deals with finding effective learning outcomes [13, 14]. This theory is based on the idea that working memory has a limited capacity to process new information received from the environment. Mental effort can be considered as an actual index of cognitive load during learning or adopting teaching content [15]. Increased mental effort is observed in students engaged on complex tasks [16]. To enable the solving of these problems, it is necessary to simplify the problem by analyzing the concepts that constitute it [17]. Depending on the working memory capacity and the structure of the task, the problem can be decomposed into multiple sub-problems [18], the number of which give rise to the problem complexity, but it is very important to take into account the interaction between the sub-problems [19].

More recently, cognitive complexity has emerged as a form of assessment of the complexity of a task. It is used to measure students' attitude and achievement in tests, which is why it is very 
important [20]; it is also applied to evaluate the difficulty of problems as well as their validation for national state tests [21]. Cognitively complex tasks require students to choose the right strategy and high levels of thinking to achieve the right solution [22]. All strategies used in problem-solving should be combined into a logical sequence to achieve the correct solution to the problem [23].

The cognitive complexity of a problem may partly determine which skills and concepts are necessary to solve the problem in order to increase the students' achievement [24]. Task characteristics related to information diversity and increasing information load contribute to the increase in the level of cognitive complexity [25]. For evaluation of the numerical rating of the cognitive complexity of a chemical problem, Cognitive Complexity Rating rubrics for the evaluation of the numerical rating of cognitive complexity are developed [26, 27]. The developed rubrics are based on Complexity Theory [28, 29] and Cognitive Load Theory [30, 31]. Complexity Theory can explain the system of multiple connected parts. The construct of intrinsic cognitive load from Cognitive Load Theory is used in the assessment of the interaction between them. In ideal research, cognitive complexity will correlate highly with students' achievement, but may not always predict all variations within the problem task and the characteristics of the respondents themselves [26]. The cognitive complexity rating can be calculated in several steps [26, 27]. Initially, it is necessary to calculate the number of concepts (or skills) required to solve the task, and then the difficulty of each concept is evaluated from the student's perspective. After this step, the rubric is used to sum the concepts in terms of difficulty, thus determining the numerical rating of difficulty of the concepts represented in the tasks as well as their interactivity. The total numerical rating of cognitive complexity is additive and is obtained by summing the numerical rating of the difficulty of the concepts and their interactivity [26].

The rubric created allows the validity and reliability of test results to be determined, so that the expert method for cognitive complexity rating can be used as a measure of objective complexity. Depending on the knowledge and experience of the expert, a task can be solved in different ways. One expert can divide the task into two "easy" steps, while another will solve the task in one "mediumdifficulty" step. Applying these rubrics, in both cases, the same numerical rating of cognitive complexity is obtained, and this characteristic can serve to improve the inter-reliability of the evaluation $[26,27]$.
Chemistry is inherently complex so an assessment of cognitive complexity is needed in education as it allows an objective rating regardless of the task evaluator. Some concepts in the task are easy, some difficult, and students are often required to understand difficult concepts that include a higher order of cognition. Assessment of cognitive complexity can be performed reliably, and if teachers apply it in the teaching process, they could have a better understanding of it [26, 27]. The teacher can gradually add concepts into the problem tasks, taking into account that the tasks to be tested upon should represent the concepts that the student has already mastered taking into account that the tasks represent the concepts that the student has mastered until the test.

Salt hydrolysis is difficult domain for students, as mentioned in literature. Previously designed procedures have been proven to be reliable methods for the assessment of the numerical rating of the cognitive complexity of problem tasks. The need to create these procedures is for two reasons: 1) the subjectivity of experts is minimized and 2) it can help teachers to introduce the concepts of the domain gradually, taking care not to overload the students' working memory capacity.

\section{EXPERIMENTAL SECTION}

\subsection{Aim of the research}

The aim of this research was the development and validation of the procedure for the assessment of the numerical rating of cognitive complexity in salt hydrolysis problems. As part of the validation process for assessing the numerical rating of the cognitive complexity of problem-solving it is necessary:

- to determine the correlation of student achievement with a numerical rating of cognitive complexity of problem tasks, and

- to determine the correlation of invested mental effort with a numerical rating of the cognitive complexity of problem tasks.

Based on the set aim, the specific tasks of the research were defined:

1) The construction of a table for assessing the difficulty of concepts represented in the problem tasks in the field of salt hydrolysis;

2) The construction of a table for assessing interactivity;

3) Combining a constructed table for assessing the difficulty of concepts with a cognitive complexity rating rubric proposed by Knaus et al. [26]; 
4) The assessment of concept interactivity in tasks;

5) Determination of the cognitive complexity of the analyzed tasks; and

6) Identification of students' misconceptions that might have influenced their test results.

\subsection{Participants}

The total sample of this research consisted of 50 students of the first and the second year (2021 years) at the Faculty of Sciences in Novi Sad, study program Basic Academic Studies of Chemistry. Students who participated in the research have mastered the concepts of salt hydrolysis during their course. Participants were from an urban population of mixed socioeconomic status and entered the survey voluntarily. The testing was anonymous.

The field of salt hydrolysis and problems related to that field are studied within the courses General Chemistry, Analytical Chemistry I and Calculation in Chemistry at the Faculty of Sciences in Novi Sad, in the Department of Chemistry, Biochemistry and Environmental Protection. In the General Chemistry and Analytical Chemistry courses, the hydrolysis of salts is covered from a theoretical point of view. Within the course Calculation in Chemistry, this concept is addressed mainly through the solving of calculations related to $\mathrm{pH}$.

\subsection{Description of the instrument}

A specially created knowledge test was used as the research instrument. The time required to complete the test was 60 minutes and it consisted of seven problems. Each correct answer scored one point, so the total maximum score on the test was 7 points. The test contained three tasks with only one correct answer, two multiple-choice tasks, and two calculation tasks. In addition to the assessment of student achievement, an assessment of mental effort was also made with the same test, using a seven-point Likert scale, which, according to Kalyuga [38], is one of the most reliable scales. After each solved or unsolved task, students were asked to evaluate the mental effort invested by selecting the appropriate descriptive mark. During the statistical analysis of the results, descriptors were coded numerically from "extremely easy" as numerical value 1 to "extremely difficult" as numerical value 7 .

The obtained results were analyzed using IBM SPSS Statistics 24 software.

\section{RESULTS AND DISCUSSION}

\subsection{Instrument validation}

Segedinac et al. [33] proposed a model for the estimation of the quality of a test by considering pre-test and post-test assurance parameters. Pre-test assurance parameters were estimated by four experts whose narrow scientific field is Chemistry Education Research (CER). The test was assessed as valid based on the consistency of the assignments with the applicable course curriculum and recommended textbooks for the realization of coursework. The test tasks were evaluated by experts as diverse, with clearly defined requirements and meaningful sentences complying with language standards.

Post-test assurance parameters were defined as basic statistical parameters: reliability coefficient, task discrimination indices, test discrimination index, task difficulty indices and test difficulty index.

Reliability is calculated as a measure of internal consistency and is expressed as Cronbach's $\alpha$ coefficient. A Cronbach's $\alpha$ value of 0.51 for achievement represents a satisfactory coefficient of reliability [34] and is acceptable when a small number of tasks are included in the test [34-38]. For self-reported mental effort, this value of the Cronbach's $\alpha$ coefficient was 0.78 , which indicates high reliability $[34,39]$. The calculated indices of item difficulty were in the range from $24 \%$ to 80 $\%$. The average value was $51.71 \%$, so the test was characterized as moderately difficult. Two tasks had an index difficulty of $>75 \%$, which characterizes them as easy, while four tasks had an index difficulty of 25-75\%, which makes them mediumdifficulty $[40,41]$. Only one task had a difficulty index of $<25 \%$, making it a difficult task. Discrimination indices were in the range 0.36-0.79. The average value was 0.49 and presented an excellent discrimination index. Six tasks had an excellent discrimination index of $>0.40$, and one task had a good discrimination index of 0.36 [41, 42]. The applied test was characterized by basic statistical parameters, which are shown in Table 1.

The normality of the distribution of the students' achievements and self-invested mental effort at the $95 \%$ confidence level is further discussed. The Shapiro-Wilk test of normality $(F=0.94 ; p=0.01)$ did not confirm the assumption of normality of distribution for students' achievements. Another way in which normal distribution is examined involves counting the number of outliers in a data set. The analysis determined the existence of mul- 
tiple hits greater than \pm 1.96 from a maximum of 5 $\%$ z-score outlier limits, which additionally did not satisfy the criterion of normal distribution [43]. Further statistical processing was guided by this result. Shapiro-Wilk test $(F=0.97 ; p=0.31)$ confirmed the assumption of normality of distribution for self-invested mental effort.

\section{Table 1}

Descriptive statistics for the students' performance and mental effort

\begin{tabular}{|c|c|c|}
\hline Parameter & $\begin{array}{c}\text { Students' } \\
\text { achievements }^{1} \\
(\mathbf{N}=\mathbf{5 0})\end{array}$ & $\begin{array}{c}\text { Students' ratings } \\
\text { of mental effort }{ }^{2} \\
(N=50)\end{array}$ \\
\hline Average & 3.62 & 3.67 \\
\hline $\begin{array}{l}\text { Standard } \\
\text { deviation }\end{array}$ & 1.62 & 0.77 \\
\hline Minimum & 1.00 & 1.57 \\
\hline Maximum & 7.00 & 5.57 \\
\hline Range & 6.00 & 4 \\
\hline
\end{tabular}

${ }^{1}$ Students' achievements could range from 0 to 7

${ }^{2}$ Possible ratings for invested mental effort could rang from 1 to 7 : extremely easy (1) to extremely difficult (7)

Validation of the research instrument was performed by observing the dependence of student achievement on self-invested mental effort. Because achievement did not satisfy normal distribution, the dependence of student achievement on average mental effort over a nonparametric Spearman's rank correlation coefficient was observed. The graphical dependence and statistical parameters of this dependence are shown in Table 2.

\section{Table 2}

Statistical parameters of the regression analysis of students' performances and their evaluation of invested mental effort

\begin{tabular}{lc}
\hline \hline Parameter & Value \\
\hline $\begin{array}{l}\text { Correlation } \\
\text { coefficient }\end{array}$ & -0.60 \\
$\boldsymbol{p}$-value & 0.00 \\
Equation & Achievement $=7.74-1.12 \times$ Mental effort \\
\hline \hline
\end{tabular}

This dependence is described by a strong correlation $\left(r_{\mathrm{s}}=-0.60 ; p=0.00\right)$. The $p$-value is less than 0.05 , indicating that there was a statistically significant correlation between student achievement and average self-perceived mental effort in the test. The existence of a significant correlation between students' achievement and mental effort has already been confirmed in studies that have focused on the validation of methods for as- sessing the cognitive complexity of problem tasks $[26,27,44-46]$.

\subsection{Table creation}

Rubrics for the assessment of numerical rating of cognitive complexity have proven to be reliable and valid for determining the numerical rating of cognitive complexity in problematic tasks in general and organic chemistry [26, 27]. However, these rubrics required additional modification in the form of tables for assessing the difficulty of concepts or skills in problem tasks and an assessment their interactivity (TADCI) based on the number of concepts represented [44-46]. The advantage of these tables relative to rubrics is that the subjectivity of teachers is minimized, and the concepts represented in tasks are precisely defined by experts. To ensure objectivity in assessing the cognitive complexity of problem tasks in the field of salt hydrolysis, a TADCI in this field has been developed (Table 3 ).

The TADCI contains three main concepts: "Types of salt", "Hydrolysis of salts" and "Calculation of $\mathrm{pH}$ and $\mathrm{pOH}$ values in salt solution". All concepts are divided into sub-concepts according to their difficulty: easy, medium and difficult. The TADCI contains the additional concept of "Solution concentration"and the interactivity of the concepts.

Assessment of the numerical rating of cognitive complexity is a procedure that consists of several steps:

1. Determination of the sub-concepts represented in the task;

2. Estimation difficulty of each subconcept using TADCI;

3. Addition of sub-concepts by difficulty in order to determine the numerical difficulty rating by the method of Knaus et al. [26];

4. Determining whether an additional concept is represented in the task and assessment of interactivity using TADCI, and

5. Addition of numerical rating of difficulty and numerical rating of interactivity in order to obtain overall numerical rating of cognitive complexity.

The difficulty rating of each sub-concept was assessed by a group of four experts - four university professors. In the assessment of the difficulty of each sub-concept, the experts assessed what a student should know to solve the task successfully from the student's perspective. Also, the complexity of the computational operation was assessed based on the number of steps the student 
should apply. It is important to note that the experts assessed the difficulty of each sub-concept independently and that the inter-rater reliability of the cognitive complexity assessment was calculated by the method of two-way mixed interclass correlation. The obtained value of Cronbach's $\alpha$ coefficient of $87 \%$ indicates a very good agreement between the experts' assessments. All disagreements in the assessment between experts were eliminated through a panel discussion. This satisfied the reliability criterion so that expert assessments of cognitive complexity could be applied in further statistical data processing.

Table 3

TADCI

\begin{tabular}{lc}
\hline \hline BASIC CONCEPT & $\begin{array}{c}\text { Sub-concept } \\
\text { difficulty }\end{array}$ \\
\hline Sub-concepts & \\
\hline Differentiation of salt types: neutral, acidic and basic & Easy \\
\hline SALT HYDROLYSIS & Easy \\
\hline Differentiation of salts into those that hydrolyze and those that do not & Easy \\
\hline Estimation of pH in a solution of salts that do not hydrolyze & Medium \\
\hline Estimation of pH in a solution of a salt of a strong acid and a weak base & Medium \\
\hline Estimation of pH in a solution of a salt of a weak acid and a strong base & Difficult \\
\hline Estimation of pH in a solution of a salt of a weak acid and a weak base & Difficult \\
\hline Writing the chemical equation of the salt hydrolysis reaction & \\
\hline CALCULATION OF pH AND pOH VALUES IN SALT SOLUTION & Medium \\
\hline Calculation of pH in a solution of a salt of a weak acid and a strong base & Medium \\
\hline Calculation of pOH in a solution of a salt of a weak base and a strong acid & Difficult \\
\hline Calculation of pOH in a solution of a salt of a weak acid and a strong base & Difficult \\
\hline Calculation of pH in a solution of a salt of a weak base and a strong acid & Difficult \\
\hline Calculation of pH in a solution of a salt of a weak base and a weak acid & \\
\hline ADDITIONAL CONCEPT & \\
\hline Concentration of solutions & \\
\hline INTERACTIVITY OF THE CONCEPTS & \\
\hline The task contains one concept & 0 \\
\hline The task contains two concepts & 1 \\
\hline The task contains three or more concepts & 2 \\
\hline \hline
\end{tabular}

The concept "Types of salt" is easy. Students were asked to differentiate salts into neutral, acidic and basic.

The concept "Salt hydrolysis" is structured in three levels (three sub-concepts). Determination of whether aqueous solutions of salts hydrolyze or not is an easy sub-concept. Also, an easy subconcept is the evaluation of the $\mathrm{pH}$ of a salt that does not hydrolyze. Estimation of $\mathrm{pH}$ of solutions of salts that can hydrolyze is medium sub-concept. Finally, the estimation of $\mathrm{pH}$ in a solution of a salt of a weak acid and a weak base, and writing the chemical equation of the salt hydrolysis reaction are difficult sub-concepts.

Sub-concepts integrated in the concept "Calculation of $\mathrm{pH}$ and $\mathrm{pOH}$ values of salt solutions" could be medium or difficult. The sub-concept is of medium difficulty when a student needs to cal- culate the $\mathrm{pH}$ value of a solution of a salt of a weak acid and a strong base or the pOH of a solution of a salt of a weak base and a strong acid. If students need to calculate the $\mathrm{pOH}$ value of a solution of a salt of a weak acid and a strong base or the $\mathrm{pH}$ of a solution of a salt of a weak base and a strong acid or the $\mathrm{pH}$ of a solution of a salt of a weak base and a weak acid, then this sub-concept is difficult. Although these two sub-concepts are similar by definition, a difference in difficulty is present because the student must use the self-ionization constant of water. This complicates the calculation and increases the number of steps that the student must take when calculating the $\mathrm{pH}$ values.

Additional concepts only affect the increase of interactivity, while their difficulty was considered negligible. These concepts were related to the calculation of the solution concentration. 
The interactivity can be nonsignificant, basic or complex, depending on the number of basic concepts present in the task. Tasks with one concept are assigned an interactivity value of 0 ; a task which contains two-concept interactivity is basic, and a numerical value of 1 is assigned; while in tasks with three or more concepts, interactivity will be complex and the numerical rating for cognitive complexity will be 2 .

After evaluating the difficulty of the subconcepts represented in the tasks and the interactivity of the concepts, the numerical value of cognitive complexity is obtained using the method of Knaus et al. [26, p. 555].

\subsection{Procedure description}

The tasks represented in the test have different levels of cognitive complexity. We are going to explain the procedure of calculating the cognitive complexity of one simple and one more complex task. An example of calculating the numerical rating of cognitive complexity will be shown in the example of Tasks 2 and 7 of the test.

Task 2. Circle the number in front of the formulas of salts which can hydrolyze. Estimate the $\mathrm{pH}$ value in the aqueous solutions of salts that can hydrolyze (whether the $\mathrm{pH}$ value of the solution is greater than or less than 7)

$$
\text { 1) } \left.\left.\left.\mathrm{Na}_{2} \mathrm{CO}_{3} ; 2\right)\left(\mathrm{NH}_{4}\right)_{2} \mathrm{SO}_{4} ; 3\right) \mathrm{Na}_{2} \mathrm{SO}_{3} ; 4\right) \mathrm{CaSO}_{4}
$$

This task contains only one basic concept: salt hydrolysis. The following sub-concepts are represented in this task:

- Differentiation of salts that hydrolyze from those that do not (easy sub-concept),

- Estimation of $\mathrm{pH}$ in a solution of a salt of a strong acid and a weak base (medium subconcept), and

- Estimation of $\mathrm{pH}$ in a solution of a salt of a weak acid and a strong base (medium subconcept).

Two sub-concepts according to TADCI are of medium difficulty, while one sub-concept is easy. This task contains one basic concept - salt hydrolysis - so interactivity is nonsignificant and is given the numerical value 0 . According to rubric designed by Knaus et al. [26], two mediumdifficulty sub-concepts have a numerical difficulty rating of 3, while one easy sub-concept has a numerical difficulty rating of 1 , so the overall numerical rating of the cognitive complexity of this task will be 4 .
Task 7. Write the chemical equation of the reaction of hydrolysis of sodium acetate. What is the pOH value of the sodium acetate solution prepared by dissolving 0.001 moles of sodium acetate in $500 \mathrm{~cm}^{3}$ of distilled water? Neglect the increase in volume due to dissolution $\left(\mathrm{K}_{\mathrm{CH}} \mathrm{CHOOH}_{\mathrm{CO}}=1.8 \cdot 10^{-5}\right)$.

The following basic concepts are represented in this task: "Salt hydrolysis" and "Calculation of $\mathrm{pH}$ and $\mathrm{pOH}$ values in salt solution". Also, the additional concept of "Solution concentration" is included in this task. The first requirement of this assignment is that the student write the chemical equation of the salt hydrolysis reaction. It is subconcept which is difficult and belongs to basic concept of "Salt hydrolysis" according to TADCI. After that, it is necessary for the student to calculate the quantitative concentration of this salt in solution. The calculation of "Solution concentration" is an additional concept. Finally, to solve this task the student needs to calculate the pOH of a solution of a salt of a weak acid and a strong base. It is a difficult sub-concept and belongs to basic concept of "Calculation of $\mathrm{pH}$ and $\mathrm{pOH}$ values in salt solution". Thus, this task contains three concepts, so interactivity is complex and is assigned a numerical value of 2 . According to the rubric of Knaus et al. [26], two difficulty concepts have a numerical difficulty rating of 5 . Therefore, the overall numerical rating of the cognitive complexity of this task is $7(5+2)$.

In the same manner, the values of cognitive complexity have been calculated for all the tasks, the results of which are summarized in Table 4.

\section{T a ble 4}

\section{Cognitive complexity ratings of salt hydrolysis tasks}

\begin{tabular}{cc}
\hline \hline Task number & Cognitive complexity rating \\
\hline $\mathbf{1}$ & 1 \\
$\mathbf{3}$ & 2 \\
$\mathbf{5}$ & \\
$\mathbf{2}$ & 4 \\
$\mathbf{4}$ & 5 \\
$\mathbf{6 , 7}$ & 7 \\
\hline \hline
\end{tabular}

\subsection{Procedure validation}

Information on the validity of the procedures for rating cognitive complexity was obtained through a combination of achievement measures and measures of mental effort [26, 27, 44-46]. In order to validate the method for assessing the numerical rating of cognitive complexity of problem tasks in the field of salt hydrolysis, it was neces- 
sary to determine the correlation between students' achievement and the cognitive complexity of the problem, as well as the correlation between students' mental effort and cognitive complexity.

As the distribution of students' achievement and mental effort did not satisfy the criterion of normal distribution, validation of the procedure by linear regression analysis could not be performed. In the first phase, an analysis of the dependence of students' achievement (independent variable) on the numerical rating of cognitive complexity (dependent variable) was performed. This is in agreement with previous research $[26,27,44-46]$. Dependence of the numerical rating of cognitive complexity on the achievements of all students (50) by task (7) was observed (350 items). A binomial (biserial) correlation analysis was performed, since the achievement values can be only 0 or 1 (depending on whether the answer is correct or not). Statistical analysis parameters are shown in Table 5 .

\section{Table 5}

Statistical parameters of the correlation analysis of students' achievements and cognitive complexity

\begin{tabular}{lc}
\hline \hline Parameter & Value \\
\hline $\begin{array}{l}\text { The correlation } \\
\text { coefficient } \\
\boldsymbol{p} \text {-value }\end{array}$ & -0.30 \\
$\begin{array}{l}\text { Equation } \\
\text { Achievement }=0.81-0.07 \times \text { Cognitive } \\
\text { complexity }\end{array}$ \\
\hline
\end{tabular}

Coefficients obtained by biserial analysis $\left(r_{\mathrm{bs}}=-0.30 ; p=0.00\right)$ indicate that there is a statistically significant correlation between students' achievement and cognitive complexity [47]. According to some studies, this value of correlation coefficient indicates a moderate correlation [48, 49]. Coefficients obtained by biserial correlation are acceptable at values of $>0.20[50,51]$. The negative value of the coefficient shows that with an increase in the numerical rating of the cognitive complexity of the problem the student achievement decreases.

The second stage of validation of the procedure for the assessment of cognitive complexity of tasks was to analyze the dependence of selfinvested mental effort on the rating of cognitive complexity of the task. Since the achievement does not satisfy normal distribution, the Spearman's $\rho$ correlation coefficient was determined. The dependence and statistical parameters are shown in Table 6.
Table 6

Statistical parameters of the correlation analysis of students' mental effort and cognitive complexity

\begin{tabular}{lc}
\hline \hline Parameter & Value \\
\hline $\begin{array}{l}\text { The correlation } \\
\text { coefficient } \\
\boldsymbol{p} \text {-value }\end{array}$ & 0.46 \\
$\begin{array}{l}\text { Equation } \\
\text { Mental effort }=2.44+0.30 \times \text { Cognitive } \\
\text { complexity }\end{array}$ \\
\hline
\end{tabular}

Spearman's $\rho$ correlation coefficient $\left(r_{\mathrm{s}}=0.46 ; p=0.00\right)$ indicates a moderate statistically significant correlation between mental effort (dependent variable) and cognitive complexity (independent variable) [47]. The positive value of the correlation coefficient indicates that with increasing cognitive complexity of tasks, students invest greater mental effort to solve the problems. As reported in previous studies, students' achievement decreases and self-invested mental effort increases with an increase in the numerical rating of cognitive complexity [26, 27, 44-46].

\subsection{Misconception identification}

Low values of achievement might be caused by misconceptions observed in the students who participated in the research. When wrong answers occur with a frequency of $>10 \%$ they can be considered misconceptions [52].

The students taking part in this research did not differentiate between types of salts, or between those that can and cannot hydrolyze. They considered that barium chloride (16\% of wrong answers), potassium sulfate (14\%) and calcium sulfate $(12 \%)$ are acidic salts. Ten percent of students thought that neutral salts such as calcium sulfate hydrolyze and that those whose aqueous solutions are basic (sodium carbonate) or acidic (ammonium sulfate) do not hydrolyze. Demircioğlu [53] found the misconception among students that they thought all salts were neutral and their aqueous solutions had no $\mathrm{pH}$ value. A similar result was found in a recent study [8].

Analysis of the results of the research revealed that students have problems with the estimation of the $\mathrm{pH}$ and $\mathrm{pOH}$ values of solutions of acidic and basic salts, as well as with the calculation of numerical values of solutions (12\% wrong answers). Students considered that high $\mathrm{pH}$ (over 7) is logical for acidic salt solutions, and that high pOH (over 7) in basic salt solution. In research by Kala et al., [54] students considered that a high pH 
value is a measure of acidity and a high $\mathrm{pOH}$ value is a measure of basicity. The $\mathrm{pH}$ value as a measure of acidity in students was noticed earlier by Garnett et al. [55]. Orwat et al. [4] reported that students, in reality, do not understand the basic concepts of acids and bases needed to understand the concept of salt hydrolysis. In research by Olić and Adamov [56], results were obtained where students were unable to estimate the $\mathrm{pH}$ of aqueous salt solutions. In this research, students estimated that aqueous solutions of copper(II) sulfate and potassium sulfite, as well as aqueous solutions of sodium acetate and zinc chloride, had the same $\mathrm{pH}$ value (20\% of wrong answers). This is similar to the research of Supatmi et al. [8] where students considered that all aqueous salt solutions had the same $\mathrm{pH}$ value of 7 . Also, students had problems in estimating the $\mathrm{pH}$ value in solutions of salts of weak bases and weak acids; namely, students did not use data on the value of the acid and base constants, so, for example, they concluded that ammonium cyanide was salt that did not hydrolyze (24\% of wrong answers). By analyzing misconceptions on salt hydrolysis, Putri [57] found that students do not know how to determine the $\mathrm{pH}$ values of aqueous solutions of salts that can hydrolyze and have difficulty understanding the ratios $K_{\mathrm{a}}$ and $K_{\mathrm{b}}$.

One of the problems that students experience is in the application of the appropriate formula when calculating $\mathrm{pOH}$ and $\mathrm{pH}$ values of acidic and basic salts (12\% of wrong answers). Students calculated the concentration of $\mathrm{OH}^{-}$ions in a solution of acidic salts as a multiplication of the basic constant and the concentration of the conjugated base, without application of the square root, thus producing incorrect results:

$$
\left[\mathrm{OH}^{-}\right]=K_{b} \times c_{b}
$$

Students calculated a pOH value of 2.87 of a solution of acid salt. They calculated the concentration of $\mathrm{H}_{3} \mathrm{O}^{+}$ions in a solution of basic salts in the same manner:

$$
\left[\mathrm{H}_{3} \mathrm{O}^{+}\right]=K_{a} \times c_{a}
$$

Thus, for basic salts, they obtained a $\mathrm{pH}$ value of $<7$, which makes no sense. These results are a confirmation of the research that students have difficulties in calculating $\mathrm{pH}$ and $\mathrm{pOH}$ values [8].

Observed misconceptions can certainly help further improvement and development of the created TADCI. Based on these results, the sub-concepts represented in this table can be divided into even simpler sub-concepts in order to obtain an even more precise estimation of numerical rating.

\section{CONCLUSIONS, IMPLICATIONS AND LIMITATIONS}

The aim of this research was the creation and validation of a procedure for the assessment of the numerical rating of cognitive complexity in the field of salt hydrolysis. Firstly, it was necessary to design the TADCI for salt hydrolysis problems. The TADCI could help teachers in evaluating the difficulty of sub-concepts represented in problem tasks in the field of salt hydrolysis and their interactivity and in calculating a numerical rating of cognitive complexity.

In order to validate this procedure, it was necessary to examine the correlation between students' achievement and the cognitive complexity of the problem, as well as the correlation between students' invested mental effort and cognitive complexity. The validity of the procedure was confirmed by correlation analysis, where the obtained values of the correlation coefficient indicated that there was a moderate statistically significant correlation between the variables. In analyzing the students' achievement and their invested mental effort, it has been observed that achievement decreased with an increased numerical rating of cognitive complexity, and at the same time, students invested a greater amount of mental effort. In order to solve tasks with a higher numerical rating of cognitive complexity, students had to invest more effort, which resulted in lower achievement.

Analyzing students' responses, some common errors were found in a number of students. These errors were considered as misconceptions if they occurred among at least $10 \%$ of students. Some students did not distinguish between types of salts or between those that are subject to hydrolysis and those that are not. They also had problems in estimating and calculating the $\mathrm{pH}$ and $\mathrm{pOH}$ values of salt solutions. They applied the wrong formulas and thus got poor results.

This research is significant for chemistry teaching because it validated the method for evaluating the numerical rating of cognitive complexity of problem tasks in the field of salt hydrolysis. In this way, teachers can easily determine a numerical rating of the cognitive complexity of a problem, which enables them to control the concepts that have been mastered by the students and to control the complexity of the problem so that overload of the student's working memory is avoided. It also helps teachers better to understand and follow students' progress in learning. A numerical solution of a problem or a circled answer often does not 
provide insight into a student's understanding of chemical concepts.

A limitation of this research was the nature of the sample of respondents; namely, students from only one study program and one educational profile were examined. Also, one of the limitations could be the expert assessment of the difficulty of the concepts represented in the problems from the perspective of students; however, this was partially overcome by a panel discussion about any disagreements in the assessment between experts and by the high value of the inter-rater reliability obtained.

The analysis of students results revealed misconceptions among students that can serve for further modification and improvements of the proposed TADCI, which contains sub-concepts that are represented only in the tasks of this test. Therefore, in further research, it would be worthwhile to pay attention to additional concepts from other domains of chemistry that may arise in hydrolysis problem tasks.

Acknowledgments. The authors acknowledge financial support of the Ministry of Education, Science and Technological Development of the Republic of Serbia (Grant No. 451-039/2021-14/ 200125).

\section{REFERENCES}

[1] D. P. Cartrette, P. M. Mayo, Students' understanding of acids/bases in organic chemistry contexts. Chem. Educ. Res. Prac., 12, 29-39 (2011). DOI: $10.1039 / \mathrm{C} 1 \mathrm{RP} 90005 \mathrm{~F}$

[2] J. M. Nyachwaya, General chemistry students' conceptual understanding and language fluency: acid-base neutralization and conductometry. Chem. Educ. Res. Pract., 17, 509-522, (2016). DOI: 10.1039/C6RP00015K

[3] C. Alvarado, F. Canada, A. Garritz, V. Mellado, Canonical pedagogical content knowledge by cores for teaching acid-base chemistry at high school, Chem. Educ. Res. Pract., 16, 603-618 (2015). DOI: $10.1039 / \mathrm{C} 4 \mathrm{RP} 00125 \mathrm{G}$.

[4] K. Orwat, P. Bernard, A. Migdal-Mikuli, Alternative conceptions of common salt hydrolysis among uppersecondary-school students. J. Balt. Sci. Educ., 16 (1), 64-76 (2017).

[5] P. C. Hardiyanti, W. Sumarni, C, Kurniawan, The Effect of Application of Problem Based Learning Model Learning on Salt Hydrolysis Material Learning Outcomes (2018). http://www.ijere.com/frontend//uploads/submissionfolde $\mathrm{r} /$ prahasti-hardiyanti/the-effect-of-application-ofproblem-based-learning-model-learning-on-salthydrolysis-material-learning-outcomes-m0YPP.docx (date of access 06.07.2019.)

[6] C. K. Chu, K. Y. Hong, Misconceptions in the teaching of chemistry in secondary school in Singapore \& Malaysia. In: Innovative Thoughts, Invigorating Teaching: Proceedings of the Sunway Academic Conference, Swan
Convention Centre, Bandar Sunway, 7 August 2009, pp. $1-10$ (2010).

[7] H. Elham, K. A. Dilmaghani, Students' misconceptions on acid-base chemistry. Basic Education College Magazine for Educational and Humanities Sciences, 43, 743753 (2019).

[8] S. Supatmi, A. Setiawan, Y. Rahmawati, Students' misconceptions of acid-base titration assessments using a two-tier multiple-choice diagnostic test. Afr. J. Chem. Educ., 9(1), 18-37 (2019).

[9] N. Seçken, Identifying student's misconceptions about SALT, Procedia Soc. Behav. Sci., 2, 234-245 (2010). DOI:10.1016/j.sbspro.2010.03.004

[10] A. Cokelez, A Comparative study of French and Turkish students' ideas on acid-base reactions, J. Chem. Educ., 87(1), 102-106 (2010). DOI: 10.1021/ed800017b

[11] N. Seçken, E. U. Alşan, The effect of constructivist approach on students' understanding of the concepts related to hydrolysis, Procedia Soc. Behav. Sci., 15, 235-240 (2011). DOI: https://doi.org/10.1016/j.sbspro.2011.03.079

[12] J. J. Gongden, E. J. Gongden, Y. N. Lohdip, Assessment of the difficult areas of the senior secondary school 2 (two) chemistry syllabus of the Nigeria science curriculum, Afr. J. Chem. Educ., 1(1), 48-61 (2011).

[13] J. van Merriënboer, P. Ayres, Research on cognitive load theory and its design implications for e-learning. Educ. Technol. Res. Dev., 53(3), 5-13 (2005). DOI: https://doi.org/10.1007/BF02504793

[14] G. Markansky, T. S. Terkildsen, R. E., Mayer, Role of subjective and objective measures of cognitive processing during learning in explaining the spatial contiguity effect. Learn. Instr., 61, 23-34 (2019).

DOI: https://doi.org/10.1016/j.learninstruc.2018.12.001

[15] P. A. Kirchner, F. Kirchner, Mental Effort. In Encyclopedia of the Sciences of Learning, N. M. Seel (Ed.), Springer, 2012, pp 2182-2184. DOI:10.1007/springerreference_226189

[16] M. C. Kernan, N. S. Bruning, L. Miller-Guhde, Individual and Group Performance: Effects of Task Complexity and Information. Human performance, 7(4), 273-289 (1994). DOI: 10.1207/s15327043hup0704_3

[17] R. J. Nadolski, P. A. Kirschner, J. J. Merrienboer, J. Woretshofer, Development of an instrument for measuring the complexity of learning tasks, Educ. Res. Eval., 11(1), 1-27 (2005).

DOI: $10.1080 / 13803610500110125$

[18] G. Sun, S. Yao, J. A. Carretero, An investigation of the relation between the complexity of problem structure and mental effort. Proceedings of the Human Factors and Ergonomics Society - 57th Annual Meeting, California, USA, 30.09.2013. (2013). DOI: $10.1177 / 1541931213571057$

[19] G. S. Halford, W. H. Wilson, S. Phillips, Processing capacity defined by relational complexity: Implications for comparative, developmental, and cognitive psychology. Behav. Brain. Sci., 21, 803-865 (1998). DOI: https://doi.org/10.1017/S0140525X98001769

[20] R. C. Daniel, S. E. Embertson, Designing cognitive complexity in mathematical problem-solving. applied 
psychological measurement, Appl. Psychol. Meas., 34(5), 348-364 (2010).

DOI: $10.1177 / 0146621609349801 \mathrm{http} / / /$ apm.sagepub.com

[21] S. E. Embertson, R. C. Daniel, Understanding and quantifying cognitive complexity level in mathematical problem solving items, Psychol. Sci. Q., 50(3), 328-334, (2008).

[22] D. Batra, Cognitive complexity in data modeling: Causes and recommendations, Requir. Eng., 12(4), 231-244 (2007). DOI: 10.1007/s00766-006-0040-y

[23] H. Hsu, E. A. Silver, Cognitive complexity of mathematics instructional task in a Taiwanese classroom: An examination of task sources, J. Res. Math. Educ., 45(4), 460-496 (2014).

DOI: $10.5951 /$ jresematheduc.45.4.0460

[24] D. C. Maynard, M. D. Hakel, Effect of objective and subjective task complexity on performance, Hum. Perform., 10(4), 303-330 (1997).

DOI: https://doi.org/10.1207/s15327043hup1004_1.

[25] R. A. Campbell, Task Complexity: A Review and analysis, Acad. Manag. Rev., 13(1), 40-52 (1988). DOI: 10.5465/AMR.1988.4306775

[26] K. Knaus, K. Murphy, A. Blecking, T. Holme, A valid and reliable instrument for cognitive complexity rating assignment of chemistry exam items, J. Chem. Educ., 88(5), 554-560 (2011). DOI: 10.1021/ed900070y

[27] J. R. Raker, J. M. Trate, T. A. Holme, K. Murphy, Adaptation of an instrument for measuring the cognitive complexity of organic chemistry exam items, J. Chem. Educ., 90(10), 1290-1295 (2013).

DOI: https://doi.org/10.1021/ed400373c

[28] N. Pippenger, Complexity theory. Sci. Am., 238 (6), 114-125 (1978).

[29] O. Goldreich, Computational Complexity: A Conceptual Perspective. Cambridge University Press, 2008.

[30] J. Sweller, Cognitive load during problem solving: Effects on learning, Cogn. Sci., 12(2), 257-285 (1988). DOI: https://doi.org/10.1207/s15516709 $\operatorname{cog} 1202 \_4$

[31] J. Sweller, P. Ayres, S. Kalyuga, Cognitive Load Theory. Springer, 2011.

[32] S. Kalyuga, Managing Cognitive Load in Adaptive Multimedia Learning. Information Science reference. (2009).

[33] M. Segedinac, M. Segedinac, Z. Konjović, G. Savić, A formal approach to organization of educational objectives, Psihologija, 44(4) 307-323, (2011). DOI: 10.2298/PSI1104307S .

[34] K. S. Taber, The use of Cronbach's alpha when developing and reporting research instruments in science education, Res. Sci. Educ., 48, 1273-1296 (2018). DOI: https://doi.org/10.1007/s11165-016-9602-2

[35] R. Ebel, D. Frisbie, Essentials of Educational Measurement. Prentice Hall, 1991.

[36] S. Moss, H. Prosser, H. Costello, N. Simpson, P. Patel, S. Rowe, S., Tuner, C. Hatton, Reliability and validity of the PAS-ADD checklist for detecting psychiatric disorders in adults with intellectual disability. J. Intellect. Disabil. Res., 42(2), 173-183. DOI: $10.1046 / j .1365-2788.1998 .00116 . x$
[37] K. M. Loewenthal, C. A. Lewis, An introduction to Psychological Tests and Scales ( $2^{\text {nd }}$ ed). Psychology Press (2001). DOI: https://doi.org/10.4324/9781315782980

[38] M. Tavakol, R. Dennick, Making sense of Cronbach's alpha, Int. J. Med. Educ., 2, 53-55. (2011). DOI: $10.5116 /$ ijme. $4 \mathrm{dfb} .8 \mathrm{dfd}$

[39] A. Jonsson, G. Svingby, The use of scoring rubrics: Reliability, validity and educational consequences, Educ. Res. Rev., 2(2), 130-144 (2002). DOI: https://doi.org/10.1016/j.edurev.2007.05.002

[40] S. S. Pande, R. P. Pande, V. P. Parate, A. N. Nikam, S. H. Agrekar, Correlation between difficulty and discrimination indices of MCQs in formative exam in physiology, SE. Asian J. Med. Educ., 7(1), 45-50 (2013).

[41] M. H. Towns, Guide to developing high-quality, reliable, and valid multiple-choice assessments, J. Chem. Educ., 91(9), 1426-1431 (2014). DOI: https://doi.org/10.1021/ed500076x

[42] A. M. Zubairi, N. L. Abu Kassim, Classical and rasch analyses of dichotomously scored reading comprehension test items, Mal. J. ELT Res., 2, 1-20 (2006).

[43] A. Mayers, Introduction to Statistics and SPSS in Psychology. Pearson Education Limited, 2013.

[44] S. A. Horvat, M. D. Segedinac, D. D. Milenković, T. N. Hrin, Development of procedure for the assessment of cognitive complexity of stoichiometric tasks, Maced. $J$. Chem. Chem. Eng., 35(2), 275-284 (2016). DOI: $10.20450 /$ mjcce.2016.893

[45] S. A. Horvat, D. D. Rodić, M. D. Segedinac, T. N. Rončević, Evaluation of Cognitive Complexity of tasks for the topic hydrogen exponent in the solutions of acids and bases, J. Sub. Did., 2(1), 33-45 (2017). DOI: $10.5281 /$ zenodo. 1238972

[46] S. A. Horvat, T. N. Rončević, D. Z Arsenović., D. D. Rodić, M. D. Segedinac, Validation of the procedure for the assessment of cognitive complexity of chemical technology problem tasks, J. Balt. Sci. Educ., 19(1), 6475 (2020). DOI: https://doi.org/10.33225/jbse/20.19.64

[47] J. D. Evans, Straightforward statistics for the behavioral sciences. Thomson Brooks/Cole Publishing Co, 1996.

[48] J. Cohen, Statistical Power Analysis for the Behavioral Sciences. Lawrence Erlbaum Associates (1988).

[49] N. Brace, R. Kemp, R. Snelgar, SPSS for Psychologists: A guide to data analysis using SPSS for Windows, (3rd ed), Routledge, 2006.

[50] J. Liu, D. J. Harris, A. Schmidt, 33 Statistical procedures used in college admissions testing, Handbk. Stat., 26, 1057-1091 (2006).

DOI: https://doi.org/10.1016/S0169-7161(06)26033-4

[51] K. Schweizer, C. DiStefano, Principles and Methods of Test Construction, Hogrefe Publishing, 2016.

[52] Y. K.Yan, R. Subramaniam, Using a multi-tier diagnostic test to explore the nature of students' alternative conceptions on reaction kinetics, Chem. Educ. Res. Pract., 19, 213-226. (2018). DOI: https://doi.org/10.1039/C7RP00143F

[53] G. Demircioglu, Comparison of the effects of conceptual change texts implemented after and before instruction on secondary school students' understanding of acid-base 
concepts, Asia-Pacific Forum Sci. Learn. Teach., 10 (2), 1-29, (2009).

[54] N. Kala, F. Yaman, A. Ayas, The effectiveness of predict-observe-explain technique in probing students' understanding about acid-base chemistry: A Case for the Concepts of $\mathrm{pH}, \mathrm{pOH}$, and strength, Int. J. Sci. Math. Educ., 11, 555-574 (2013).

DOI: https://doi.org/10.1007/s10763-012-9354-z

[55] P. J. Garnett, P. Garnett, M. W. Hackling, Students'alternative conceptions in chemistry: A review of research and implications for teaching and learning, Stud, Sci. Educ., 25(1), 69-96, (1995).

DOI: $10.1080 / 03057269508560050$

[56] S. Olić, J. Adamov, The relationship between learning styles and students' chemistry achievement, Maced. $J$. Chem. Chem. Eng., 37(1), 79-88, (2018). DOI: $10.20450 /$ mjcce.2018.1400

[57] Y. R. Putri, Analyzing of students' misconceptions on salt hydrolysis chemistry at senior high school in Padangsidempuan (Thesis). Universitas Medan, 2014. 